volume fraction of each phase present in the mixture. This deviation is attributed to impurities and imperfections introduced during the processing steps rather than to the nature of the dispersed phase per se. The slight increase in T.C.R. observed in most dispersion-strengthened golds (see Table III) can also be explained by the presence of impurities. It is also well known that the thermal e.m.f. of gold is extremely sensitive to impurities, particularly at elevated temperatures. Therefore the small e.m.f. differences observed for dispersion-strengthened golds compared with the control sample of pure gold may not be significant.

\section{Conclusion}

This investigation shows that the addition of a stable oxide dispersion in gold improves very dramatically the hardness, strength and wear resistance of the composite as compared with pure gold without decreasing appreciably some of the important intrinsic properties of gold such as oxidation resistance and electrical (and thus the thermal) conductivity. We have shown that superior mechanical properties can be obtained when 1.0 volume per cent of an oxide dispersoid is added to gold and that conventional cold working techniques can be used.

The properties of dispersion-strengthened gold suggest its use for applications requiring good mechanical properties (tensile and/or hardness) at low or elevated temperatures $\left(500\right.$ to $600^{\circ} \mathrm{C}$ ), combined with low electrical resistance and oxidation resistance at high temperature. Other possible electrical and electronic applications would include its use in connectors, high temperature conductors, electrodes, thermocouples and bonding wire. Many applications within the chemical industry may also develop for dispersion-strengthened gold laboratory apparatus.

In respect to electrical contact applications, we have determined that oxide-strengthened gold affords a greater resistance to arc erosion with lower tendency to sticking and welding.

Furthermore, compared with pure gold, it has an equivalent thermal and electrical conductivity and a reasonably low contact resistance. The outstanding electrical contact properties of dispersion-strengthened gold will be described in detail in a later paper.

\section{References}

1 N. Fuschillo and M. L. Gimpl, f. Mater. Sci., 1970, 5, (12), 1078

2 M. L. Gimpl and N. Fuschillo, f. Metals, 1971, 23, (6), 39

3 M. Poniatowski and M. Clasing, Gold Bull., 1972, 5, (2), 34

4 U.S. Patent 2,947,114 Engelhard Industries, 1960

5 U.S. Patent 2,984,894 Engelhard Industries, 1961

6 U.S. Patent 3,049,577 Engelhard Industries, 1962

7 U.S. Patent 3,201,236 Engelhard Industries, 1965

8 U.S. Patent 3,606,766 Engelhard Industries, 1971

9 C. Larson, Gold Bull., 1975, 8, (4), 127

\title{
The Surface Self-Diffusion of Gold
}

\section{EFFECT OF ADSORBED TRACES OF BISMUTH}

For some years G. E. Rhead, of the University of Paris, has been active in the study of the remarkable effects of adsorbed impurities on surface self-diffusion of metals. He has found, for instance, that traces of chlorine, bromine, and iodine can promote very high rates of self-diffusion on copper surfaces over the temperature range 380 to $1050^{\circ} \mathrm{C}$. On silver surfaces, traces of sulphur have a similar accelerating effect.

It is, however, on gold surfaces that some of the most dramatic changes are observed, and in a recent note from his laboratory (Comptes Rendus [C], 1975, 280, 489) Jean-Paul Biberian reports that the presence of a monolayer of adsorbed bismuth increases the coefficient of surface self-diffusion at 600 to $950^{\circ} \mathrm{C}$ by a factor of as much as 10,000 .

In the experiments described, an electrolytically polished sample of pure gold, 99.999 fine, was maintained for 1 to 10 hours at a steady temperature in the region studied. A slow stream of argon at atmospheric pressure was used to transport bismuth vapour (derived by passing it over bismuth at a lower temperature than that of the gold) over the gold.

The effect of this treatment was to develop deep grooves, flanked with mounds banked-up above the level of the gold surface along the grain boundaries. By measuring the depth and width of the grooves and the height of the mounds the coefficient of surface self-diffusion could be calculated.

There are two main explanations for this effect-that a "two-dimensional" compound having a low melting point is formed covering the surface with a "molten" layer, one atom thick, in which individual atoms move freely, or that some substrate atoms climb on top of the adsorbed layer and can then "jump" or "skate" or otherwise migrate by distances of the order of 100 atoms. Rhead considers that there is still insufficient evidence to decide which is correct.

Whatever may be the explanation, these observations may be of considerable importance in connection with powder metallurgy. The nature of the forces responsible for eliminating voids during heat treatment has long been a matter of debate but undoubtedly surface diffusion plays an important role in the mechanism of the sintering process.

Thus adsorbed layers derived from sintering atmospheres may have a significant effect, hitherto unappreciated, on the consolidation of metallic powder compacts.
J. C. C. 